\title{
Use of azithromycin in the treatment of acute exacerbations of COPD
}

\author{
Aaron $\mathrm{P}$ Milstone \\ Division of Allergy, Pulmonary \\ and Critical Care, Vanderbilt \\ University Medical Center, \\ Nashville, TN, USA
}

Correspondence:Aaron Milstone

Vanderbilt University Medical Center, 913

Oxford House, Nashville, TN 37232, USA

$\mathrm{Tel}+\mathrm{I} 6159360393$

Fax +I 6159360396

Email aaron.milstone@vanderbilt.edu

\begin{abstract}
Chronic bronchitis is a relatively common entity among patients with underlying chronic obstructive lung disease. Typical treatment includes pulmonary hygiene, bronchodilators, and antimicrobial therapy. In recent years, the duration of antimicrobial therapy in acute exacerbations of COPD has become shorter and shorter. This review summarizes the data on the use of the drug azithromycin for this particular patient population with a focus on 3-day and single-day therapy.
\end{abstract}

Keywords: COPD acute exacerbation, macrolide, azithromycin

\section{Background}

Millions of people in the US suffer from chronic obstructive pulmonary disease and the prevalence of chronic bronchitis estimated to be greater than $3 \%$ (Soriano et al 2003). Patients with chronic bronchitis may experience exacerbations (AECBs) of their lung disease with typical complaints of increased dyspnea, productive cough and purulent sputum (Anthonisen et al 1987). Treatment of all types of exacerbations with antimicrobial agents remains debated but a recent meta-analysis by Saint et al (1995) confirmed the need for antibacterial treatment in the most severe cases of AECB (Type 1). About 50\% of patients with chronic bronchitis will have at least 2 exacerbations per year (DeAbate et al 2000; Kreis et al 2000), with 20\% of these episodes resulting in hospitalizations (Kreis et al 2000). About half of all patients discharged from the hospital for treatment of the exacerbation are readmitted more than once within the following 6 months (Snow et al 2001). It also appears that frequent AECBs can be associated with a more fulminate decline in $\mathrm{FEV}_{1}$ compared to patients without exacerbations (Kanner et al 2001; Donaldson et al 2002). Thus, effective treatment of the AECB and consideration for prevention of AECB are major goals in the care of patients with chronic obstructive lung disease.

Since its introduction into the US antibiotic market in 1991, azithromycin has had multiple indications and formulations (Drug Details 2006). As a 5-day course (5-day formulation; Z pack $^{\circledR}$ ) the drug was indicated for the treatment of adults with mild to moderate community acquired pneumonia (CAP), acute exacerbations of chronic bronchitis (AECB) and acute bacterial sinusitis (ABS). Additionally, a 3-day formula $\left(\right.$ TriPak $\left.^{\circledR}\right)$ and a single dose $\left(\mathrm{Zmax}^{\circledR}\right)$ have been made available in the US in recent years. The 3-day dosing is indicated for both AECB and ABS whereas the single dose does not currently carry a US FDA indication for the treatment of AECB. These shorter courses of the drug were used in Europe and elsewhere in the world since the early 1990s. Today, these products are available as generics and it is unlikely that future re-formulations of azithromycin will be added to the antibiotic market. This review will evaluate the use of azithromycin in its various formulations for the treatment and prevention of acute exacerbations of COPD. 


\section{Zpack $^{\circledR}$ - 5-day formulation}

The 5-day formulation of azithromycin was the original formulation introduced in the US. At the time of its introduction most acute exacerbations of chronic bronchitis were treated with antimicrobial agents such as tetracyclines, beta lactams, and sulfa drugs. Early trials found that the 5-day formulation of this macrolide was well tolerated and efficacious (Dark 1993; Whitlock 1995). Further, Destache et al (1999) showed in a retrospective study that newer agents, including azithromycin, significantly impacted AECB in terms of decreased hospitalization rates, longer time between $\mathrm{AECB}$ episodes and lower total cost for treatment of the exacerbation. More recent studies have focused on respiratory fluorquinolones as the major comparator to Zpack ${ }^{\circledR}$. Recent studies by DeAbate et al (2000) and Amsden et al (2003) have shown that macrolide antibiotics maintain very good clinical and bacteriological cure rates compared to quinolones. In the Amsden study, levofloxacin was used as a comparator and early cure rates were similar in both arms. Early cure rates were similar between both antibiotics; $89 \%$ of azithromycin-treated patients and $92 \%$ of levofloxacin-treated patients $(\mathrm{p}=0.22)$. The test of cure in this study (day 24) again showed no significant difference between the favorable response rates for the two treatment groups ( $82 \%$ vs $86 \%$, respectively; $\mathrm{p}=0.53$ ). Bacteriological eradication rates did not differ for the two agents when Haemophilus influenza, Streptococcus pneumonia, and Mycobacterium catarrhalis were cultured and evaluated. Interestingly, over half of all enrolled patients in both arms of the study were active smokers but all enrolled patients had to have $\mathrm{FEV}_{1}>35 \%$ (during exacerbation free testing periods). DeAbate et al (2000) evaluated 5-day azithromycin versus a similar duration of the fluroquinolone, moxifloxacin. The study population in this study included adults with chronic bronchitis. No mention of $\mathrm{FEV}_{1}$ was given in this study and like the Amsden study, approximately $50 \%$ of patients in both antibiotic arms were active smokers. Early clinical cure rates were not significantly different; azithromycin $92 \%$ and moxifloxacin $91 \%$. The clinical success of the drugs was maintained to the test of cure (days 14-21 post therapy). Microbiological success was very good for both agents although there was a difference between the two drugs for Haemophilus parainfluenzae (azithromycin $62 \%$, moxifloxacin $88 \%$ ). One study has compared azithromycin efficacy to another macrolide, dirithromycin. In this five center study, investigators found that clinical success was not statistically different between the two drugs early (Day 7) or late (Day 30). A summary of the major studies comparing the 5-day formulation of azithromycin to various comparators is shown in Table 1.

\section{TriPak $^{\circledR}$ - 3-day formulation}

In more recent years, azithromycin has been available as a 3-day formulation in the US. The 3-day formulation has a number of advantages over the 5-day formulation of the drug. First compliance is virtually assured with such a short course of antibiotic therapy. In addition, pharmacokinetic studies have shown that the serum and granulocyte drug concentrations are significant different between the two dosing methods (Amsden et al 1999). Table 2 shows 11 various studies comparing the 3-day formulation with various comparators including amoxicillin, amoxicillin-clavulanate, and other macrolides. The efficacy of the 3-day formulation has ranged between 67.6 and $100 \%$ for patients cured or improved from AECB at early study time points ( $<12$ days). Late efficacy (or test of cure) is maintained at levels between $77 \%$ and $96 \%$. In all of these studies the 3-day formulation is generally well tolerated with only a minimal increase in gastrointestinal side effects compared with the 5-day formulation.

Although not shown on Table 2, one study has evaluated the clinical efficacy of the 3-day formulation in patients with very severe COPD (Cazzola et al 2005). This study by

Table I Clinical response rates (percent cured and improved) for azithromycin (5-day formulation) versus various comparator(s) at early and late time points

\begin{tabular}{|c|c|c|c|c|c|c|c|}
\hline \multirow[t]{2}{*}{ Study } & \multirow[t]{2}{*}{ Year } & \multirow[t]{2}{*}{ Comparator } & \multicolumn{2}{|c|}{$\begin{array}{l}\text { Azithromycin } \\
\text { 5-day formulation }\end{array}$} & \multicolumn{2}{|c|}{ Various comparators } & \multirow[t]{2}{*}{$\begin{array}{l}\text { Definition of chronic } \\
\text { bronchitis }\end{array}$} \\
\hline & & & Early & Late & Early & Late & \\
\hline Dark & 1993 & Cefaclor & 100.0 & NS & 92.0 & NS & NS \\
\hline Whitlock & 1995 & $\begin{array}{l}\text { Amoxicillin- } \\
\text { clavulanate }\end{array}$ & 100 & 90.0 & 93.0 & 85.0 & ATS \\
\hline DeAbate et al & 2000 & Moxifloxacin & 92.0 & 88.0 & 91.0 & 88.0 & ATS \\
\hline Amsden et al & 2003 & Levofloxacin & 88.9 & 81.9 & 92.4 & 85.6 & ATS \\
\hline Castaldo et al & 2003 & Dirithromycin & 75.7 & 86.5 & 84.8 & 95.5 & ATS \\
\hline
\end{tabular}

Abbreviations: ATS, American Thoracic Society; NS, not stated. 
Table 2 Clinical response rates (percent cured and improved) for azithromycin (3-day formulation) versus various comparator(s) at early and late time points

\begin{tabular}{|c|c|c|c|c|c|c|c|}
\hline \multirow[t]{2}{*}{ Study } & \multirow[t]{2}{*}{ Year } & \multirow[t]{2}{*}{ Comparator } & \multicolumn{2}{|c|}{$\begin{array}{l}\text { Azithromycin } \\
\text { 3-day formulation }\end{array}$} & \multicolumn{2}{|c|}{ Various comparators } & \multirow[t]{2}{*}{$\begin{array}{l}\text { Definition of } \\
\text { chronic bronchitis }\end{array}$} \\
\hline & & & Early & $\overline{\text { Late }}$ & Early & Late & \\
\hline Mertens et al & 1992 & amoxicillin & 100.0 & 96.0 & 92.0 & 80.0 & ATS \\
\hline Bradbury & 1993 & clarithromycin & 95.0 & NS & 97.0 & NS & NS \\
\hline Beghi et al & 1995 & amoxicillin-clavulanate & 67.6 & NS & 97.3 & NS & NS \\
\hline Biebuyck & 1996 & amoxicillin-clavulanate & 92.1 & 95.7 & 86.4 & 79.6 & ATS \\
\hline Gris & 1996 & amoxicillin-clavulanate & 86.0 & NS & 92.0 & NS & ATS \\
\hline Zachariah & 1996 & amoxicillin-clavulanate & 94.0 & NS & 93.0 & NS & ATS \\
\hline Laurent & 1996 & roxithromycin & NS & 91.2 & 88.8 & NS & NS \\
\hline Hoepelman et al & 1997 & amoxicillin-clavulanate & 95.0 & 77.0 & 90.0 & 66.0 & ATS \\
\hline Cazzola et al & 1999 & dirithromycin & 92.5 & 89.2 & 90.0 & 94.4 & ATS \\
\hline Schouenborg et al & 2000 & pivampicillin & 93.0 & 78.0 & 86.0 & 81.0 & ATS \\
\hline Swanson et al & 2005 & clarithromycin & 93.0 & 85.0 & 94.0 & 82.0 & ATS \\
\hline Zervos et al & 2007 & moxifloxacin & 93.0 & 89.0 & 84.0 & 73.0 & $\begin{array}{l}\text { Anthonisen et al } \\
1987\end{array}$ \\
\hline
\end{tabular}

Abbreviations: ATS, American Thoracic Society; NS, not stated.

Cazzola et al revealed that $17 / 21(81 \%)$ episodes of acute exacerbations in 65 adult COPD patients were either cured or improved at an early time point (3-5 days post therapy). Patients enrolled in this study had severe to very severe lung disease based on American Thoracic Society criteria and had all received the 23-valent pneumococcal capsular polysaccharide vaccine. Bacteria isolated from the sputum of patients with acute exacerbations showed a variety of pathogens including gram negative bacteria and S. aureus. No $S$. pneumoniae was isolated from the sputum of patients enrolled in this study who had acute exacerbations of their COPD. The main impact of this type of study is that it is more typical of a "real world" scenario; one where most patients with advanced COPD/AECB have received vaccination against pneumococcus. Other groups have attempted to simulate more real world scenarios and gauge AECB outcomes not just on pure clinical or bacteriological criteria but to also use health related quality of life (Grossman et al 1998; Milstone et al 2005; Spencer and Jones 2003). One of these observational studies, was a prospective, multicenter, observational study evaluating outpatient adults with AECB who received either 3 days of AZM $500 \mathrm{mg} / \mathrm{d}$ or 5- to 14-day courses of standard antibiotics (usual care) as directed by a clinician (Milstone et al 2005). Patients with AECB treated with a 3-day course of azithromycin experienced significant improvements in health related quality of life as measured by a clinical important difference on the St. George's respiratory questionnaire and the SF-36 compared with baseline.
An additional area of interest with the 3-day formulation of azithromycin is the paradox between in vitro antibiotic resistance and in vivo success. Most antibiotic resistance surveillance programs have demonstrated substantial resistance rates for $\mathrm{S}$. pneumoniae and $\mathrm{H}$. influenzae to the macrolide class of antibiotics (Doern et al 2001; Low et al 2002; Jacobs 2003; Powis et al 2004; Low 2004). Despite these bacteriological trends, clinical response to macrolide therapy remains adequate (as indicated by the late clinical cure rates shown in Table 2 - range $77 \%-96 \%$ ). Two suggested mechanisms for the paradox between the "petri" dish and the patient exist in the literature. One is the high rate of efflux mediated (mef type) resistance among North American isolates of pneumococcus (Lantero et al 1998) in contrast to Europe where most macrolide resistance is methylation mediated (erm type). This type of bacterial resistance can be overcome by increasing drug concentration in serum or white blood cells. The second factor in this disparity is that pharmacodynamic differences among the macrolide class at the site of infection plays a critical role in predicting clinical success. Classic macrolides such as erythromycin are time dependent, ie, the amount of time the drug concentration is above the MIC for the organism determines optimal activity. In contrast, for the azalide, azithromycin, optimal activity is dependent on maximizing the area under the concentration-time above the MIC curve (AUIC) (Craig 1997). The dosing regimens of these agents are designed to maximize these pharmacodynamic parameters. Foulds et al (1990) have 
showed that tissue concentrations were above the $\mathrm{MIC}_{90}$ for all relevant community-acquired respiratory pathogens, including pneumococci, for at least 8 days after a single 500 mg oral dose of azithromycin (Foulds et al 1990). Thus, the combined effects of overcoming efflux mediated resistance with the unique pharmacodynamic properties of azithromycin make it difficult to rely on standard in vitro assessments of bacteriologic susceptibility. The most current bacterial resistance/surveillance studies have started to assess the prevalence of the various mechanisms of macrolide resistance (ie, efflux versus methylation) (Farrell, 1996). However, few studies on macrolide resistance evaluate each individual macrolide thus ignoring the potential pharmacodynamic differences of each drug in this class.

\section{Zmax $^{\circledR}$ - I-day formulation}

A single dose preparation of azithromycin is now also available for utilization in the treatment of respiratory infections. In 2005, the US FDA approved this formulation of the drug for both acute bacterial sinusitis and community acquired pneumonia in adults. The drug is given as a single 2-g dose and the drug is released into the gastrointestinal tract using microsphere technology to minimize side effects (Zmax package insert). Serum and white blood cell concentrations of the 2-g/1-day formulation are substantially higher than the 3-day formulation of azithromycin (Liu et al 2007). Theoretically, this early peak effect (first 24 hours) may be beneficial to the patient as bacterial burden is likely highest in the first days of treatment of an acute exacerbation. A single study has now been published which evaluates the efficacy of a 1-day formulation for the treatment of AECB (Zeros et al 2005). The comparator in this study is oral levofloxacin which is given for 7 days. In this double-blind, double dummy study comparable clinical cure agents for the two antibiotics were seen late (Days 14-21; 93.6\% for azithromycin and $92.7 \%$ for levofloxacin). Even in cases of very severe airflow obstruction $\left(\mathrm{FEV}_{1}<30 \%\right)$, azithromycin success rates were high $(>88 \%)$.

\section{Azithromycin and prophylaxis for AECB}

Data are limited about prophylaxis with azithromycin for exacerbations of chronic bronchitis. However, the drug has been used as a prophylactic agent in the cystic fibrosis population to reduce the risk of respiratory exacerbations with moderate success (Wolter et al 2002; Saiman et al 2003; Equi et al 2002). There have also been at least two trials in patients with obstructive lung disease due to bronchiectasis (Davies and Wilson 2004).
In one study conducted at the Royal Brompton, London, UK, infectious exacerbations decreased from a mean of 0.71 per month to 0.13 per month $(\mathrm{p}<0.001)$ in 33 patients on 4 months of drug prophylaxis (12 days continuous therapy followed by $250 \mathrm{mg}$ on Mondays, Wednesdays, and Fridays). An additional study in bronchiectasis utilized twice weekly azithromycin (500 mg dose) for a period of 6 months (Cymbala et al 2005). Exacerbation incidence and sputum volume measurements were compared from baseline to the end of the study. Among the eleven patients analyzed in this study azithromycin significantly decreased the incidence of exacerbations compared with usual medications ( 5 vs $16 ; \mathrm{p}=0.019$ ). Mean sputum volume over a 24 -hour 1 period also decreased by approximately $15 \%$ $(p=0.005)$. However, one small European study does suggest a benefit to treating patients with COPD with $500 \mathrm{mg} /$ day for 3 days every 3 weeks (Gomez et al 2000). This study evaluated 54 patients with moderate COPD who were treated during a single winter season. Both hospital admissions and the number of acute infectious exacerbations of COPD were statistically decreased in the azithromycin arm of the study compared to a non-treated control group.

Theoretically, it is possible that the efficacy of azithromycin in these different patient populations (cystic fibrosis and bronchiectasis) may be more related to its immunomodulatory effect rather than its antimicrobial effect. Azithromycin and the other macrolides can decrease neutrophil chemotaxis and infiltration into the respiratory epithelium, downregulate adhension molecule expression and enhance neutrophil apoptosis (Koch et al 2000; Amsden 2005). All of these factors may play significant roles in exacerbations of COPD. To this end, the National Heart, Lung, and Blood Institute and the COPD Clinical Research Network is currently enrolling patients in a multi-center investigation to determine if azithromycin decreases the rate of exacerbations over a 1-year time period (Clinical trials 2007). In this prospective, randomized, double-blind, placebo-controlled study over 1,000 patients with at least moderately severe COPD will be enrolled. Secondary endpoints will include measures of quality of life, the incidence of macrolide-resistant bacterial colonization and cost-effectiveness. Optimistically, this type of trial design will help to definitively determine if prophylactic macrolide therapy can prevent or delay the time between COPD exacerbations.

\section{Conclusion}

Azithromycin is a available in three major formulations (1-day, 3-day, and 5-day). All three have had significant success in 
AECB trials against a wide variety of comparators. Given rising concern about bacterial resistance; the higher strength preparations of azithromycin prescribed over a shorter duration of time offer considerable pharmacodynamic advantages. Future studies will assist in determining the efficacy of this drug in the prevention of exacerbations of chronic bronchitis.

\section{Disclosures}

The author has no conflicts of interest to report.

\section{References}

Amsden GW, Baird IM, Simon S, et al. 2003. Efficacy and safety of azithromycin vs levofloxacin in the outpatient treatment of acute bacterial exacerbations of chronic bronchitis. Chest, 123:772-7.

Amsden GW, Nafziger AN, Foulds G. 1999. Pharmacokinetics in serum and leukocyte exposures of oral azithromycin, 1,500 milligrams, given over a 3- or 5-day period in healthy subjects. Antimicrob Agents Chemother, 43:163-5.

Amsden GW. 2005. Anti-inflammatory effects of macrolides - an underappreciated benefit in the treatment of community-acquired respiratory tract infections and chronic inflammatory pulmonary conditions? J Antimicrob Chemother, 55:10-21.

Anthonisen NR, Manfreda J, Warren CPW, et al. 1987. Antibiotic therapy in exacerbations of chronic obstructive pulmonary disease. Ann Intern Med, 106:196-204.

Beghi G, Berni F, Carrutu L, et al. 1995. Efficacy and tolerability of azithromycin versus amoxicillin/clavulanic acid in acute purulent exacerbation of chronic bronchitis. J Chemother, 7:146-52.

Biebuyck XA. 1996. Comparison of azithromycin and co-amoxiclav in the treatment of acute tracheobronchitis and acute infectious exacerbations of chronic bronchitis in adults. Azithromycin Study Group. J Int Med Res, 24:407-18.

Bradbury F. 1993. Comparison of azithromycin versus clarithromycin in the treatment of patients with lower respiratory tract infection. J Antimicrob Chemother, 31(Suppl E):153-62.

Castaldo RS, Celli BR, Gomez F, et al. 2003. A comparison of 5-day courses of dirithromycin and azithromycin in the treatment of acute exacerbations of chronic obstructive pulmonary disease. Clin Ther, 25:542-57.

Cazzola M, Salzillo A, De Giglio C, et al. 2005. Treatment of acute exacerbation of severe-to-very severe COPD with azithromycin in patients vaccinated against Streptococcus pneumoniae. Respir Med, 99:663-9.

Cazzola M, Vinciguerra A, Di Perna F, et al. 1999. Comparative study of dirithromycin and azithromycin in the treatment of acute bacterial exacerbations of chronic bronchitis. J Chemother, 11:119-25.

Clinical trials [online]. http://clinicaltrials.gov/ct/gui/search?term=azithro mycin. Accessed December 2006.

Craig WA. 1997. Postantibiotic effects and the dosing of macrolides, azalides, and streptogramins. In Zinner SH, Young LS, Acar JF et al (eds). Expanding indications for the new macrolides, azalides, and streptogramins New York: Marcel Dekker. pp. 27-38.

Cymbala AA, Edmonds LC, Bauer MA, et al. 2005. The disease-modifying effects of twice-weekly oral azithromycin in patients with bronchiectasis. Treat Respir Med, 4:117-22.

Dark D. 1993. zithromycin versus cefaclor in the treatment of acute exacerbations of chronic obstructive pulmonary disease. Curr Ther Res, 53:203-11.

Davies G, Wilson R. 2004. Prophylactic antibiotic treatment of bronchiectasis with azithromycin. Thorax, 59:540-1.

DeAbate CA, Mathew CP, Warner JH, et al. 2000. The safety and efficacy of short course (5-day) moxifloxacin versus azithromycin in the treatment of patients with acute exacerbations of chronic bronchitis. Respir Med, 94:1029-37.
Destache CJ, Dewan N, O’Donohue WJ, et al. 1999. Clinical and economic considerations in the treatment of acute exacerbations of chronic bronchitis. J Antimicrob Chemother, 43(Suppl A):107-13.

Doern GV, Heilmann KP, Huynh HK, et al. 2001. Antimicrobial resistance among clinical isolates of Streptococcus pneumoniae in the United States during 1999-2000, including a comparison of resistance rates since 1994-1995. Antimicrob Agents Chemother, 45:1721-9.

Donaldson G, Seemungal TA, Bhowmik A, et al. 2002. Relationship between exacerbation frequency and lung function decline in chronic obstructive disease. Thorax, 57:847-52.

Drug Details. FDA Home Page. 2006 [online]. Accessed: December 2006. Available from: http://www.accessdata.fda.gov/scripts/cder/drugsatfda/ index.cfm?fuseaction=Search.DrugDetails.

Equi A, Balfour-Lynn IM, Bush A, et al. 2002. Long term azithromycin in children with cystic fibrosis: a randomised, placebo-controlled crossover trial. Lancet, 360(9338):978-84.

Farrell DJ, File TM, Jenkins SG. 2006. Prevalence and antibacterial susceptibility of mef(a)-positive macrolide-resistant Streptococcus pneumoniae over 4 years of the PROTEKT US Study (2000-2004). JClin Microbiol, 45:290-3.

Foulds G, Shepard RM, Johnson RB. 1990. The pharmacokinetics of azithromycin in human serum and tissues. J Antimicrob Chemother, 25(Suppl A):73-82.

Gomez J, Banos V, Simarro E, et al. 2000. Prospective, comparative study (1994-1998) of the influence of short-term prophylactic treatment with azithromycin on patients with advanced COPD. Rev Esp Quimioter, 133:79-83.

Gris P. 1996. Once-daily, 3-day azithromycin versus a three-times-daily, 10-day course of co-amoxiclav in the treatment of adults with lower respiratory tract infections: results of a randomized, double-blind comparative study. J Antimicrob Chemother, 37(Suppl C):93-101.

Grossman R, Mukherjee J, Vaughan D, et al. 1998. A 1-year community-based health economic study of ciprofloxacin vs usual antibiotic treatment in acute exacerbations of chronic bronchitis: the Canadian Ciprofloxacin Health Economic Study Group. Chest, 113:131-41.

Hoepelman IM, Mollers MJ, van Schie MH, et al. 1997. A short (3-day) course of azithromycin tablets versus a 10-day course of amoxycillinclavulanic acid (co-amoxiclav) in the treatment of adults with lower respiratory tract infections and effects on long-term outcome. Int $J$ Antimicrob Agents, 9:141-6.

Jacobs MR. 2003. Worldwide trends in antimicrobial resistance among common respiratory tract pathogens in children. Pediatr Infect Dis $J$, 22:S109-S19.

Kanner R, Anthonisen N, Connett J. 2001. Ower respiratory illnesses promote FEV1 decline in current smokers but not ex-smokers with mild chronic obstructive pulmonary disease. Am J Respir Crit Care Med, 164:358-64.

Koch CC, Esteban DJ, Chin AC, et al. 2000. Apoptosis, oxidative metabolism and interleukin-8 production in human neutrophils exposed to azithromycin: effects of Streptococcus pneumoniae. J Antimicrob Chemother, 46:19-26.

Kreis SR, Herrera N, Golzar N, et al. 2000. for the Therapeutic Circles Bronchitis Study Group. A comparison of moxifloxacin and azithromycin in the treatment of acute exacerbations of chronic bronchitis. JCOM, 7:33-37.

Lantero M, PortilloA, Gastañarea MJ, et al. 1998. MLS resistance phenotypes and mechanisms in S. pneumoniae. In Program and Abstracts of the Fourth International Conference on the Macrolides, Azalides, Streptogramins and Ketolides, Barcelona, Spain, 1998. Abstract 3.10, Wallace Communications, Inc., Atlanta, GA.

Laurent K. 1996. Efficacy, safety and tolerability of azithromycin versus roxithromycin in the treatment of acute lower respiratory tract infections. J Antimicrob Chemother, 37(Suppl C):115-24.

Liu P, Allaudeen H, Chandra R, et al. 2007. Comparative pharmacokinetics of azithromycin in serum and white blood cells of healthy subjects receiving a single-dose extended-release regimen versus a 3-day immediate release regimen. Antimicrob Agents Chemother, 51:110-8. 
Low DE, de Azavedo J, Weiss K, et al. 2002. Antimicrobial resistance among clinical isolates of Streptococcus pneumoniae in Canada during 2000. Antimicrob Agents Chemother, 46:1295-301.

Low DE. 2004. Resistance trends in Haemophilus influenzae (PROTEKT years 1-3 (1999-2002). J Chemother, 16(Suppl 6):49-61.

Mertens JC, van Barneveld PW, Asin HR, et al. 1992. Double-blind randomized study comparing the efficacies and safeties of a short (3-day) course of azithromycin and a 5-day course of amoxicillin in patients with acute exacerbations of chronic bronchitis. Antimicrob Agents Chemother, 36:1456-9.

Milstone A, Patsimas J, Farzan D; the PROPeR Use Study Group. 2005. Prospective observational study of patient-reported outcomes for azithromycin versus usual care in the treatment of bacterial acute exacerbation of chronic bronchitis. Clin Ther, 27:926-39.

Powis J, McGeer A, Green K, et al. 2004. In vitro antimicrobial susceptibilities of Streptococcus pneumoniae clinical isolates obtained in Canada in 2002. Antimicrob Agents Chemother, 48:3305-11.

Saiman L, Marshall BC, Mayer-Hamblett N, et al. 2003. Azithromycin in patients with cystic fibrosis chronically infected with Pseudomonas aeruginosa: a randomized controlled trial. JAMA, 290:1749-56.

Saint S., Bent S, Vittinghoff E. 1995. Antibiotics in chronic obstructive pulmonary disease: a meta-analysis. $J$ Am Med Assoc, 273:957-60.

Schouenborg P, Gerdes N, Rasmussen H, et al. 2000. Azithromycin versus pivampicillin in the treatment of acute exacerbations of chronic bronchitis: a single-blind, double-dummy, multicentre study. J Int Med Res, 28:101-10.

Snow V, Lascher S, Mottus-Pilson C. 2001. for the Joint Expert Panel on COPD of the American College of Chest Physicians and the American College of Physicians-American Society of Internal Medicine. The evidence base for management of acute exacerbations of COPD: Clinical practice guideline, part 1. Chest, 119:1185-9.
Soriano JB, Davis KJ, Coleman B, et al. 2003. The proportional Venn diagram of obstructive lung disease: two approximations from the United States and the United Kingdom. Chest, 124:474-81.

Spencer S, Jones PW; GLOBE Study Group. 2003. Time course of recovery of health status following an infective exacerbation of chronic bronchitis. Thorax, 58:589-93.

Swanson RN, Lainez-Ventosilla A, De Salvo MC, et al. 2005. Once-daily azithromycin for 3 days compared with clarithromycin for 10 days for acute exacerbation of chronic bronchitis: a multicenter, double-blind, randomized study. Treat Respir Med, 4:31-9.

Whitlock W. 1995. Ulticenter comparison of azithromycin and amoxicillin/ clavulanate in the treatment of patients with acute exacerbations of chronic obstructive pulmonary disease. Curr Ther Res, 56:985-95.

Wolter J, Seeney S, Bell S, et al. 2002. Effect of long term treatment with azithromycin on disease parameters in cystic fibrosis: a randomised trial. Thorax, 57:212-6.

Zachariah J. 1996. A randomized, comparative study to evaluate the efficacy and tolerability of a 3-day course of azithromycin versus a 10-day course of co-amoxiclav as treatment of adult patients with lower respiratory tract infections. J Antimicrob Chemother, 37(Suppl C):103-13.

Zeros M, Breen JD, Jorgensen DM, et al. 2005. Novel, single-dose microsphere formulation of azithromycin versus levofloxacin for the treatment of acute exacerbations of chronic bronchitis. Infect Dis Clin Pract, 13:1-7.

Zervos M, Martinez FJ, Amsden GW, et al. 2007. Efficacy and safety of 3-day azithromycin versus 5-day moxifloxacin for the treatment of acute bacterial exacerbations of chronic bronchitis. Int $J$ Antimicrob Agents, 29:56-61.

Zmax package insert. Accessed December 2006. URL:www.Pfizer.com. 